\title{
Usage of Predictive Scrutiny to Further Business
}

\author{
Amarendra Mohanty, P. Ranjana
}

\begin{abstract}
Conceptual-Predictive investigation is a gathering of techniques that utilizations measurable and other unique systems to foresee future sports, in view of past occasions.

Prescient exam can produce crucial records for the management of a production community organisation to beautify fundamental management. this may be beneficial for hobby guaging, deformity recognition, amplifying gear esteem, preventive guide, enhance showcasing methodologies, maintain purchaser and associated secondary promoting management in employer.
\end{abstract}

Catchphrases-Predictive evaluation; massive statistics; sample; records; choice, business; IoT("net of things); R, Python

\section{CREATION}

Prescient examination joins an collection of measurable techniques from modeling, $\mathrm{AI}$ and facts mining that take a look at gift and actual facts so that you can decide designs; foresee about future result and styles. Prescient systematic does not display to you what will occur in a while. It estimates what can also arise in a while with a pleasant degree of dependability. It distinguishes capacity dangers and open doorways for an enterprise organization. This likewise betters get customers, gadgets, accomplices and marketplace. frequently the hard to recognize event of intrigue is in some time, however prescient exam can be associated with an hard to understand whether or no longer it's far in advance than, present or future.

\section{HISTORY}

The extreme hassle for industry is to preserve up greater seasoned gives statistics. establishments can't make step by step prescient models to estimate the hobby due to absence of more established offers facts records. institutions frequently shut down their machines for useful resource. This machine non-public time orders an charge to companies because of declined profitability and can be for the maximum element difficult in each customer objects and complicated assembling supply chains. directors in resource focused ventures often express that the critical operational threat to their agencies is abrupt disappointments in their advantages.

Institutions more regularly than not flopped in spotting damaged gadgets in addition to decide the great variables that impact the success or sadness of the method. retaining the consumer is the significant take a look at for establishments.

We didn't have any research identified with consumer behavior before. institutions often confronting troubles in shape impeccable version and that they have no exceptional approach to accomplish more promoting procedures. in this examination we've clarified how we're in a position to make use of prescient studies through using large facts Analytical units R and Python.

\section{Enterprise Business Analytics - Solution Coverage across the Manufacturing Value Chain}

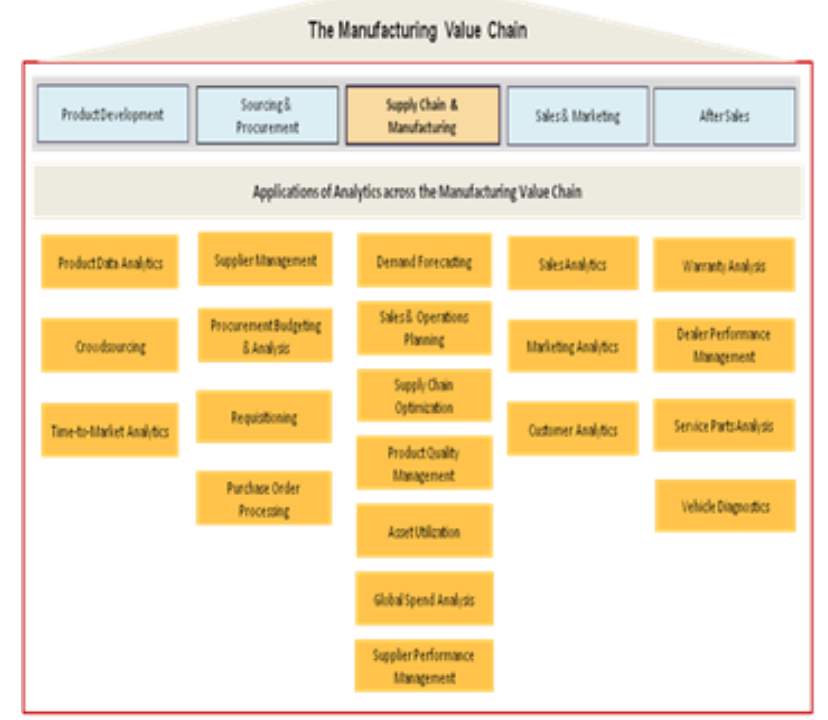

Figure 1: The Manufacturing Value Chain

\section{Excessive Level Elements In Industrial Organization}

\section{A. Call For Forecasting}

Makers need to promote their objects. Request is regularly occasional or recurrent. In such times, knowing how outer factors, as an instance, oil fees, climate, the consumer fee file and pinnacle charge have to have an impact on your consumer's commercial organization request can assist in asset challenge in assembling. Prescient examination takes recorded gives data and applies types of relapse to foresee destiny offers depending on beyond gives. Brilliant prescient modelers find out greater calculates that impacted offers the beyond and observe those factors to expected offers models. 


\section{B. Preventive upkeep}

Gifted walking stock chains count on critical process for the consistent benefits. A hurry of latest information created by means of manner of the "net of things" (iot) can provide non-prevent estimation and transmission of records from remote assets on particular elements of technology bureaucracy. Present iot statistics is essentially broke down by way of manner of facts researchers to get prepared prescient fashions of numerous sadness situations. The ones prescient models are then used to survey the upcoming gushing facts from the hardware. On the off hazard that a ability flaw is recognized, a message can be sent to the administrator and preservation workforce, or an interest can be made to right away shutdown the tool to abstain from harming the capital aid and further stressful era relying upon the sort.

\section{Hold clients}

Prescient examination can help now not totally to draw within the new business, yet moreover assist to maintain the clients. The primary-run thru offers are changed over into repeating profits. A great way to practice prescient exam for consumer protection, groups first need to gather data on their customers, along with insights concerning the items and administrations a patron sold (e.g., charge and logo), geographic facts, statistic and whether they're first-time or returning customers. A 'rating' may be delivered by way of way of utilizing prescient research to these information which shows how probably a client is to make more buys. In slight of customer conduct, they will be targeted with custom designed promoting efforts, much like particular item or administration proposals, terrific refund and markdown gives. Giving custom designed messages on birthdays, gives, limits and so on can help cultivate faithfulness and fend off the clients from your opponents.

\section{D.Disease location}

Records mining can help in distinguishing the examples that lead toward recognizing the deformities and capability unhappiness in assembling hardware. This system allows in distinguishing faulty items in addition to determine the massive variables that effect the fulfillment or unhappiness of the process. The prescient research way for watching for sadness and flaw area is primarily based upon information this is commonly amassed at a few stage inside the normal interest of gadget apparatuses. Instances of the type of statistics accumulated in this example include temperature, vibration degrees, acoustic data, share of powers, diversions, and other comparable specialized belongings of statistics

\section{E. Maximizing system rate}

Assembling designers make use of pretty a chunk in their time upgrading the estimation of gear inside the manufacturing line. With prescient examination and the sort of gadgets being created to recognize it, corporations can expect the focuses at which equipment start to placed on out, allowing them to actualize preventive attention faster. This can permit the hardware to be grinding away for longer timeframes without discontinuous close downs for repair.

\section{F. Optimize advertising strategies}

Agencies can build their asset record with the aid of way of expanding the gain on their showcasing speculations. An increasing range of organizations are accumulating statistics from their showcasing endeavors and utilising prescient studies to all the more likely recognize their clients and the way to talk with them all the extra appropriately and successfully.

Advertisers these days can accumulate tremendous facts approximately shoppers through internet page, net based totally life sporting sports exam apparatuses, on line systems, opinions and electronic mail crusade consequences. Corporations can likewise study the acquisition examples of consumer or buy comparable facts from outsider assets. Utilising prescient examination, advertisers can alternate those facts into worthwhile testimonies, much like who are likely going to buy a selected object or management, purchaser inclination and so forth.

Organizations can reputation on the exclusive fragments of their purpose marketplace with step by step compelling customized informing by using manner of making use of this statistics. Prescient exam can likewise show which promoting efforts and channels are best at riding gives. At closing, this will assign a greater amount of selling spending plan to endeavors that yields a better move again.

\section{RESULTS \& DISCUSSIONS}

The subsequent are a part of the prescient studies calculation fashions which may be applied within the planning of prescient fashions.

\section{A. Time collection using python}

The instance records are utilized to offer the python pandas data body version to research 10 years crude oil prices of wti and brent.

Degree 1: create an exceed expectations record item.

Degree 2 - parse the principle sheet.

Stage 3-rename the sections to of take a look at file

Diploma 4-reduce off the preliminary 18 strains due to the reality the ones columns

Comprise nan esteems at the brent expenses.

Level five-index the informational index via date.

Stage 6-cast off the date phase after re-ordering.

Diploma 7-visualize the data with seaborn. 


\begin{tabular}{|c|c|c|c|}
\hline 4 & A & B & C \\
\hline 1 & & \multicolumn{2}{|l|}{ Data 1: Crude Oil } \\
\hline 2 & Sourcekey & RWTC & RBRTE \\
\hline 3 & Date & $\begin{array}{l}\text { Cushing, OK WTI } \\
\text { Spot Price FOB } \\
\text { (Dollars per Barrel) }\end{array}$ & $\begin{array}{l}\text { Europe Brent Spot } \\
\text { Price FOB (Dollars } \\
\text { per Barrel) }\end{array}$ \\
\hline 4 & Jan-1986 & 22.93 & \\
\hline 5 & Feb-1986 & 15.46 & \\
\hline 6 & Mar-1986 & 12.61 & \\
\hline 7 & Apr-1986 & 12.84 & \\
\hline 8 & May-1986 & 15.38 & \\
\hline 9 & Jun-1986 & 13.43 & \\
\hline 10 & Jul-1986 & 11.59 & \\
\hline 11 & Aug-1986 & 15.1 & \\
\hline 12 & Sep-1986 & 14.87 & \\
\hline 13 & Oct-1986 & 14.9 & \\
\hline 14 & Nov-1986 & 15.22 & \\
\hline 15 & Dec-1986 & 16.11 & \\
\hline 16 & Jan-1987 & 18.65 & \\
\hline 17 & Feb-1987 & 17.75 & \\
\hline 18 & Mar-1987 & 18.3 & \\
\hline 19 & Apr-1987 & 18.68 & \\
\hline 20 & May-1987 & 19.44 & 18. \\
\hline 21 & Jun-1987 & 20.07 & 18. \\
\hline 22 & Jul-1987 & 21.34 & 19. \\
\hline 23 & Aug-1987 & 20.31 & 18. \\
\hline 24 & Sep-1987 & 19.53 & 18. \\
\hline 25 & Oct-1987 & 19.86 & 18. \\
\hline 26 & Nov-1987 & 18.85 & 17. \\
\hline 27 & Dec-1987 & 17.28 & 17. \\
\hline 28 & Jan-1988 & 1713 & 16 \\
\hline
\end{tabular}

Figure 2: Sample Data of WTI and Brent

Source: Prices for Crude Oil and Petroleum Products

Figure 3: 10 Years Crude oil prices chart of WTI and Brent.

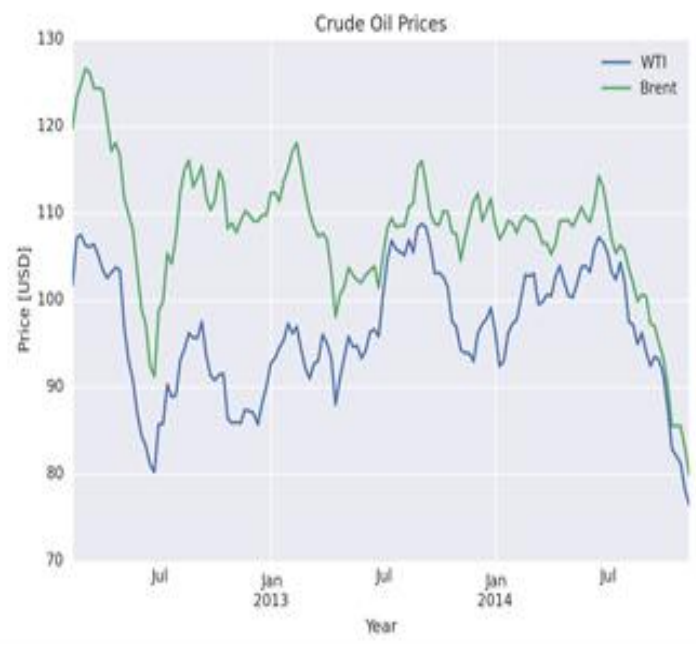

Figure 4: 3 Years Crude oil prices chart of WTI and Brent

\section{A. Logical Regression Model using $R$}

This phase explains the way to are expecting the shopping electricity of a consumer the usage of logistic regression in R.

under are the steps required to acquire this setup.

Step 1: Import the records

Step 2: test for sophistication bias
Step three: Create schooling and test samples

Step 4: Compute facts fee to discover vital variables.

Step 5: build logit models and expect on check records

Step 6: determine on optimum prediction opportunity cutoff for the model. Step 7: Do version diagnostics.

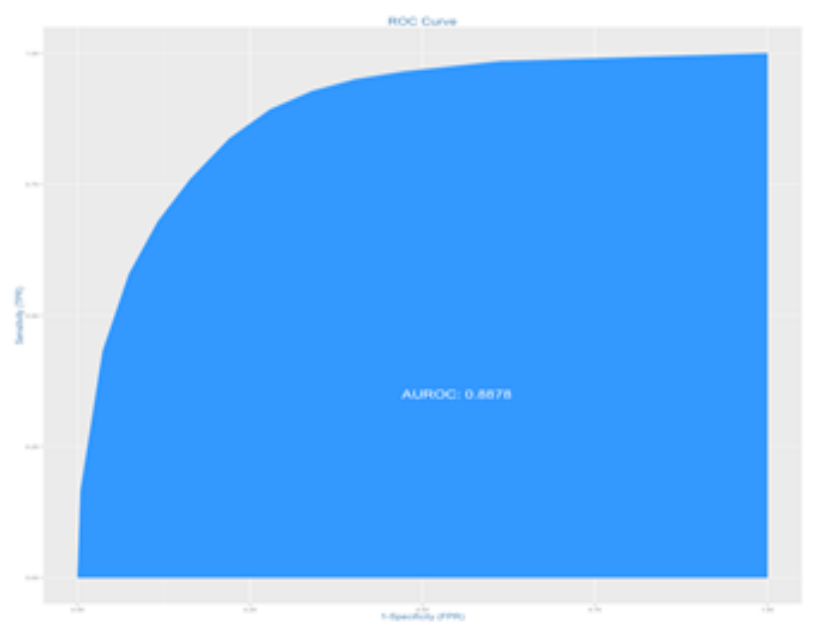

Figure 5: ROC curve

ROC Curve (Receiver working traits) - ROC bend, is a graphical plot that outlines the presentation of a twofold classifier framework as its segregation region is shifted. The bend is made with the aid of plotting the genuine powerful rate (TPR) against the artificial high-quality fee (FPR) at high-quality restrict settings.

TPR (proper amazing fee) - Sensitivity (furthermore called the real high-quality price, the evaluation, or probability of recognition in certain fields) measures the quantity of positives which is probably successfully extremely good all things taken into consideration (e.g., the quantity of wiped out those who are effectively recognized as having the scenario).

FPR(fake top notch price) - the unreal great rate is decided as the share between the quantity of bad sports wrongly sorted as powerful (fake positives) and certainly the range of real terrible occasions (paying little apprehend to association)

\section{CONCLUSION AND SUBSEQUENT STEPS}

There can be a buzz in recent times if the ones prescient techniques actually energy worth or they may be most effective an unfilled speak. It appears to be glaring that prescient research have positively affected commercial business enterprise considering that the exceptional 'ol days. it's far moreover positive that the effect will increment exponentially as facts, fashions, strategies and AI preserve on enhancing dependent on improvement. The hobby for prescient examination will clean over the enterprise and take the commercial business enterprise better than ever. The market heads preserve on advancing their push to change facts and observe examination with increasing modernity.

A brief depiction has given at the most proficient technique to create prescient fashions in an enterprise utilizing of the cutting-edge-day calculations (for instance Time collection and Logistic relapse calculations) in Python and R. an 
increasing number of prescient fashions may be created relying on the commercial organization conditions thru utilizing severa devices like SAS, Map/R, Python and R. The yield of these prescient models can be contrasted and the regular information for instance gushing from outdoor worldwide into big records space. or but business enterprise records. association can utilize the units like Apache Kafka and Strom for spilling way and might make use of any of the devices in Hadoop reverberation framework for bunch managing..

\section{REFERENCES}

1. James Manyika, Michael Chui, Brad Brown, Jacques Bughin, Richard Dobbs, Charles Roxburgh, Angela Hung Byers, "large data: the subsequent boondocks for development, opposition, and efficiency", McKinsey international Institute, may additionally 2011.

2. David Turner, Michael Schroeck and Rebecca Shockley, "exam: this gift reality utilization of massive information in budgetary administrations", IBM international employer offerings industrial company Analytics and Optimization govt report, may also 2013.

3. Vincent Charles, Tatiana Gherman, "assignment aggressive advantage via large statistics", center-East journal of clinical research 16 (eight): 1069-1074, 2013.

4. Thomas H. Davenport, Jill Dyche, " massive facts in big businesses ", worldwide Institue for Analytics, may additionally moreover 2013 .

5. Hsinchun Chen, Roger H. L. Chiang, Veda C. tale, " company INTELLIGENCE AND ANALYTICS: FROM huge facts TO massive effect, business enterprise Intelligence studies

6. Elena Geanina ULARU, Florina Camelia PUICAN, Anca APOSTU, Manole VELICANU, " perspectives on large facts and huge statistics Analytics", Database structures mag vol. III, no. four/2012 3

7. Bernice Purcell, " The improvement of "large records" innovation and exam ", mag of generation research.

8. studying Predictive Analytics with Python thru Joseph Babcock Eaton, Deroos, Deutsch, Lapis, Zikopoulos, " information huge statistics: Analytics for large business organization elegance Hadoop and gushing information ",2012.

9. Modeling techniques in Predictive Analytics: business enterprise troubles and answers with $\mathrm{R}$ (feet Press Analytics) with the aid of manner of Thomas W. Mill operator. 